\title{
The Effect of Halbach Array Configuration on Permanent- Magnet Synchronous Generator (PMSG) Outer-Runner
}

\author{
Syamsyarief Baqaruzi ${ }^{1,2 *}$, Afit Miranto ${ }^{1}$, Dede Wahyuda ${ }^{1}$ \\ ${ }^{I}$ Department of Electrical Engineering, Institut Teknologi Sumatera, Indonesia \\ ${ }^{2}$ Research and Innovation Center for Conservation and Renewable Energy, Institut Teknologi Sumatera, Indonesia \\ *Corresponding author E-mail: syamsyarief.baqaruzi@el.itera.ac.id
}

\begin{abstract}
Manuscript received 23 Feb 2021; revised 2 March. 2021; accepted 15 March 2021. Date of publication 2 April 2021

Permanent-Magnet Synchronous Generator it can provide highly reliable power generation with small in size, no copper losses in the rotor circuit, no need for external excitation. We designed and simulated the PMSG with 12 slots and 8 poles with an alternating polarity magnet configuration: NN-SS-NN-SS-NN-SS-NN-SS-NN-SS-NN magnetic flux per pole in the outer stator and the inner stator has been assumed to be constant, following sizes and materials described in this paper. The generator's number of poles is determined by stacking several sections of the magnet side by side and grouping opposite poles in a continuous pattern. the initial design of the PMSG 12 slots and 8 poles outer-runner compare to see how the halbach array configuration changes the output parameter, it will be included. Proportional to the load size and speed The larger the magnetic flux generated by the movement of the magnetic field, the higher the rpm, and the heavier the coil magnetic flux obtained, the higher the induced voltage. This research use five speed variations varying from 1000 to $5000 \mathrm{rpm}$ and load variation from $5 \mathrm{ohm}, 15 \mathrm{ohm}, 30 \mathrm{ohm}, 60 \mathrm{ohm}$, and $100 \mathrm{ohm}$. With the effect that the flux distribution is voltage generated at a $5 \mathrm{ohm}$ load only increases at $1000 \mathrm{rpm}$, while the increase in torque produces an increase in the amount of input power at $30 \mathrm{ohm}$, which is equal to both the speed and the amount of torque, where the input power increases at all speeds at a load of $30 \mathrm{ohm}$. This also arises when the output power generated at a load of $30 \mathrm{ohm}$ increases by a high efficiency of over $86 \%$.
\end{abstract}

Keywords: PMSG, Generator, Magnetic Flux, Halbach Array, Speed Variations

\section{Introduction}

Some areas that have varying wind speeds every second, such as in Indonesia, can be sufficient for small-scales wind power plant energy to be built, the impact is using of renewable energy is therefore increasing including research about wind turbine generator[1]. A suitable generator for this situation is called a Permanent-Magnet Synchronous Generator or commonly known as PMSG[2][3]. In raising the output level of high efficiency because there is no loss of excitation produced so widely used in general, the electromagnet is the phenomenon of current through the wire to create a magnetic field that is concentrated in the center of the coil, the more and more the number of windings around the magnetic core is made of a ferromagnetic material that causes magnetic flux core focus to make the magnet stronger. Stacked magnet cores and plates fabricated of steel sheets layers are integrated into the joining, diminishing non-magnetic holes and lowering the idling current[4] [6].

PMSG is a type of permanent magnet synchronous machine used in wind power applications that has a higher efficiency and a simpler and more robust structure. The high-energy permanent magnets in are buried inside the rotor component, Some of these parameters are very much influenced by the shape of the stator and rotor, type of material, type of topology, type of magnetic configuration and others that can be applied to a generator PMSG. Force magnetic field that is created by moving electric charges and magnetic dipoles, and exerts a force on other nearby moving charges and magnetic dipoles. The effect of the air-gap magnetic flux density value, permanent magnet working point, torque angle, and magnet embrace on magnet thickness and air-gap size was also studied with 36 slots and 4 poles designed including rotor-speed stability improvement although[7] [9].

The goal of this analysis was to see how PMSG's we are designed is influenced by the performance parameters. In order for it to be seen compared a synchronous reluctance generator for wind applications with adding halbach array configuration. We limitation on this paper studied is the effect of changes in the PMSG 12 slots and 8 poles outer-runner: the dimensions, and magnetic configuration on the resulting voltage, current, torque, strength, performance, and magnetic flux per pole in the outer stator and the inner stator has been assumed to be constant. 
This paper studied are a concept of a PMSG with 12 slots and 8 poles with an alternating polarity magnet configuration: NN-SS-NN-SS was analyzed in this paper, which was modelled and simulated using FEM-based electromagnetic software. The topology and operating principle of PMSG outer-runner will be introduced in Methods. Result and Discussion will be devoted to the design of the PMSG outerrunner. In Conclusion we summarize the paper and points out the future research direction.

\section{Methods}

Basic simulation of electromagnetic components such as C-core, E-core, and the like is used to consider the idea of producing magnetic fields and magnetic flux in electrical components before designing the electrical components of a generator. Faraday's law, also known as the law of electromagnetic induction, states that a magnetic field that increases over time will cause an electric motive force (EMF) equal to the rate of change of magnetic flux. Faraday's law is written as equation:

$$
\begin{aligned}
\varepsilon & =-N \frac{\Delta \emptyset}{\Delta t} \\
\lambda & =N . \phi \\
\varepsilon & =\frac{d \lambda}{\Delta t}
\end{aligned}
$$

Where $\varepsilon$ is the induced emf (Volt), $\mathrm{N}$ is the number of turns, $\Delta \emptyset$ is the change in magnetic flux (Wb), $\Delta t$ is the time interval (s). The negative sign only shows the direction of the electromotive force generated. If the magnetic flux is replaced to pass through the coil or coil, and the amount of magnetic flux received by the coil which causes the emf is called linkage flux, Where $\mathrm{d} \lambda$ is defined as the change in linkage flux (Wb). As for when an electric charge moves at a certain distance through a magnetic field, it is subjected to Lorentz's Force law is written as an equation:

$$
\begin{aligned}
& F=q v B \times \sin \alpha \\
& \phi=B \times A \times \operatorname{Cos} \theta
\end{aligned}
$$

This magnetic field can create a magnetic flux in the surrounding area as it is moved at a certain speed, because the field area is not perpendicular to the magnetic field and forms an angle, the magnetic flux is expressed by equation (5). Where B is the magnetic field (T), $\Phi$ is the magnetic flux present in the component $(\mathrm{Wb})$, A is the cross-sectional area $\left(\mathrm{m}^{2}\right), \theta$ is the angle formed by B and A. The relationship between flux density and magnetic field intensity will always exist in every other material.

This generator uses a permanent magnet-generated excitation field rather than an electrified coil-generated excitation field. This is one of the advantages of being able to minimize copper losses; as a result, permanent magnet generators can be much more effective than generators that use coils as an excitation field; in comparison, PMSG can be used in wind turbines with non-constant speeds. Since the voltage and power factor provided by the PMSG can be adjusted to suit we needs. Figure 1 shown how we construct designed of PMSG.
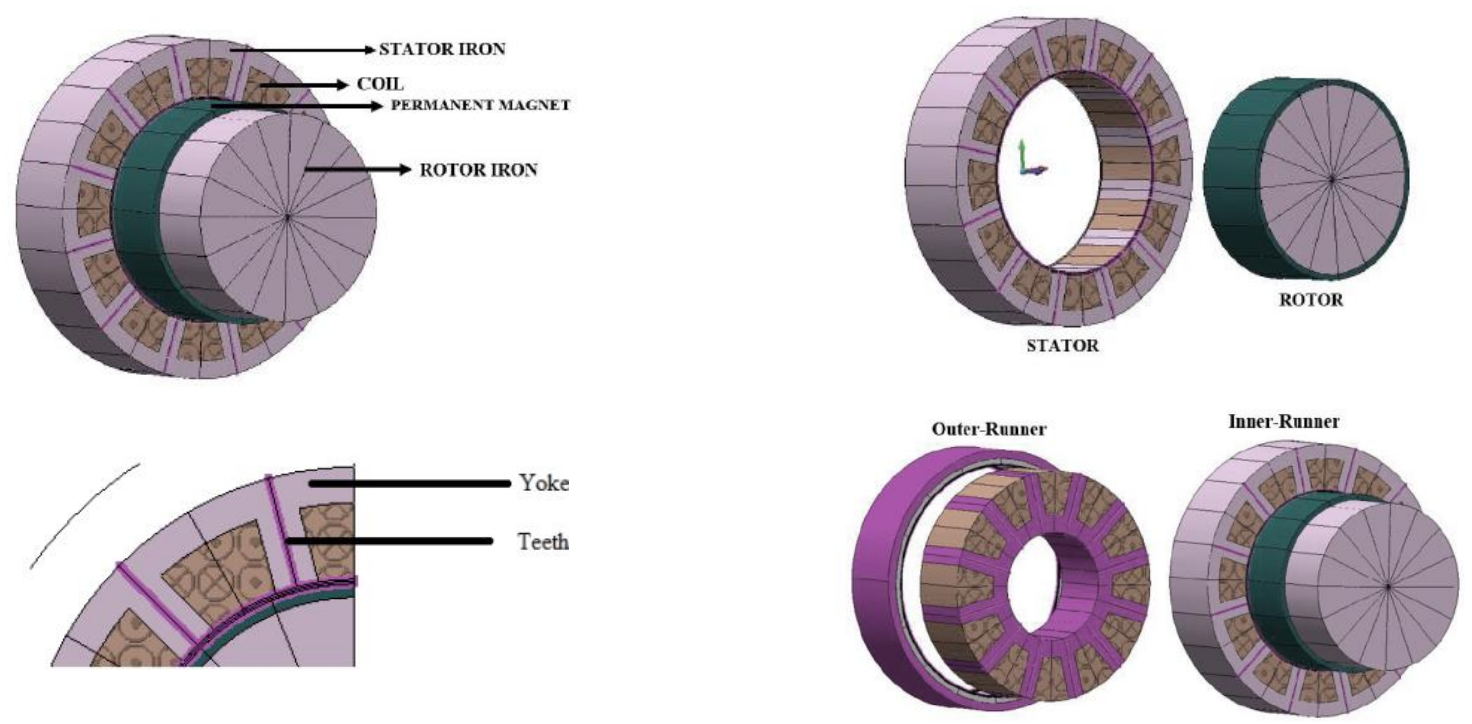

Fig 1. The Basic Construct Designed of PMSG

Since the air distance between the inner stator and the rotor is equal, the maximum magnetic flux per pole in the outer stator and the inner stator has been assumed to be constant. The flux linkage per turn in both windings has been assumed to be the same. On axial rotation, the figure above shown crankshaft will rotate the inner stator by the necessary angle[10]. The PMSG designed in this paper has the following specifications: with 12 poles and 8 slots with magnet polarity alternating configuration: NN-SS-NN-SS-NN-SS-NN-SS-NN-SS-NN- with sizes and materials described in Table 1, which is modeled and simulated using FEM-based electromagnet software. The number of poles on the generator is generated by piling several parts of the magnet side by side and arranging opposite poles in a continuous manner. The Alternating Polarity arrangement is a type of magnetic path configuration that is typically found in generators or motors. It produces a magnetic flux that is almost identical in both field directions.

Table 1. PMSG 12S 8P Outer-Runner Preliminary Design Measurement Specifications

\begin{tabular}{ccccc}
\hline No. & Component & Material & Magnitude & Thickness \\
\hline \multirow{2}{*}{ Rotor Airbox } & Air & Outer Diameter & $180 \mathrm{~mm}$ & $23,5 \mathrm{~mm}$ \\
& & & Inner Diameter & $133 \mathrm{~mm}$ \\
\end{tabular}




\begin{tabular}{|c|c|c|c|c|c|}
\hline \multirow[t]{2}{*}{2} & \multirow[t]{2}{*}{ Rotor Iron } & \multirow[t]{2}{*}{ Carpenter: Silicon steel } & Outer Diameter & $150 \mathrm{~mm}$ & \multirow[t]{2}{*}{$5 \mathrm{~mm}$} \\
\hline & & & Inner Diameter & $140 \mathrm{~mm}$ & \\
\hline \multirow[t]{2}{*}{3} & \multirow[t]{2}{*}{ Permanent Magnet } & \multirow{2}{*}{$\begin{array}{l}\text { Neodymium Iron Boron: } \\
48 / 11\end{array}$} & Outer Diameter & $140 \mathrm{~mm}$ & \multirow[t]{2}{*}{$3 \mathrm{~mm}$} \\
\hline & & & Inner Diameter & $134 \mathrm{~mm}$ & \\
\hline \multirow[t]{2}{*}{4} & \multirow[t]{2}{*}{ Virtual Rotor Airgap } & \multirow[t]{2}{*}{ Virtual Air } & Outer Diameter & $134 \mathrm{~mm}$ & \multirow[t]{2}{*}{$0,25 \mathrm{~mm}$} \\
\hline & & & Inner Diameter & $133,5 \mathrm{~mm}$ & \\
\hline \multirow[t]{2}{*}{5} & \multirow[t]{2}{*}{ Rotor Airgap } & \multirow[t]{2}{*}{ Air } & Outer Diameter & $133,5 \mathrm{~mm}$ & \multirow[t]{2}{*}{$0,25 \mathrm{~mm}$} \\
\hline & & & Inner Diameter & $133 \mathrm{~mm}$ & \\
\hline \multirow[t]{2}{*}{6} & \multirow[t]{2}{*}{ Stator Airgap } & \multirow[t]{2}{*}{ Air } & Outer Diameter & $133 \mathrm{~mm}$ & \multirow[t]{2}{*}{$0,25 \mathrm{~mm}$} \\
\hline & & & Inner Diameter & $132,5 \mathrm{~mm}$ & \\
\hline \multirow[t]{2}{*}{7} & \multirow[t]{2}{*}{ Virtual Stator Airgap } & \multirow[t]{2}{*}{ Virtual Air } & Outer Diameter & $132,5 \mathrm{~mm}$ & \multirow[t]{2}{*}{$0,25 \mathrm{~mm}$} \\
\hline & & & Inner Diameter & $132 \mathrm{~mm}$ & \\
\hline \multirow[t]{2}{*}{8} & \multirow[t]{2}{*}{ Stator } & \multirow[t]{2}{*}{ Carpenter: Silicon steel } & Outer Diameter & $132 \mathrm{~mm}$ & \multirow[t]{2}{*}{-} \\
\hline & & & Inner Diameter & $62 \mathrm{~mm}$ & \\
\hline \multirow[t]{2}{*}{9} & \multirow[t]{2}{*}{ Stator Airbox } & \multirow[t]{2}{*}{ Air } & Outer Diameter & $133 \mathrm{~mm}$ & \multirow[t]{2}{*}{$66,5 \mathrm{~mm}$} \\
\hline & & & Inner Diameter & $0 \mathrm{~mm}$ & \\
\hline 10 & Teeth & Carpenter: Silicon steel & Lenght & $25 \mathrm{~mm}$ & $10 \mathrm{~mm}$ \\
\hline \multirow[t]{2}{*}{11} & \multirow[t]{2}{*}{ Yoke } & \multirow[t]{2}{*}{ Carpenter: Silicon steel } & Outer Diameter & $82 \mathrm{~mm}$ & \multirow[t]{2}{*}{$10 \mathrm{~mm}$} \\
\hline & & & Inner Diameter & $62 \mathrm{~mm}$ & \\
\hline 12 & Coil & $\begin{array}{l}\text { Copper: } 5.77 \mathrm{e} 7 \\
\text { Siemens/meter }\end{array}$ & Turn & 100 Turn & - \\
\hline
\end{tabular}

The magnet would develop magnetic field lines on both sides from its magnetic poles with this arrangement. The magnetic flux travels by seeking the shortest path to the opposite pole, the effect can be shown in the distribution of magnetic flux seen in Figure 2, The number of poles on the generator is generated by piling several parts of the magnet side by side and arranging opposite poles in a continuous manner. The alternating polarity arrangement is a type of magnetic path configuration that is typically found in generators or motors. It produces a magnetic flux that is almost identical in both field directions[11][12]. where there is an accumulation of magnetic flux in the rotor region, shown by the red component, which occurs due to the rotor's small area magnetic flux trajectory. Though this magnetic field stress is produced in such a way that the two plates are apart from each other, the stress occurs in definite areas. Repulsion forces are generated between magnetic poles with the same polarities, while attraction forces are generated between polarities with different polarities[13].

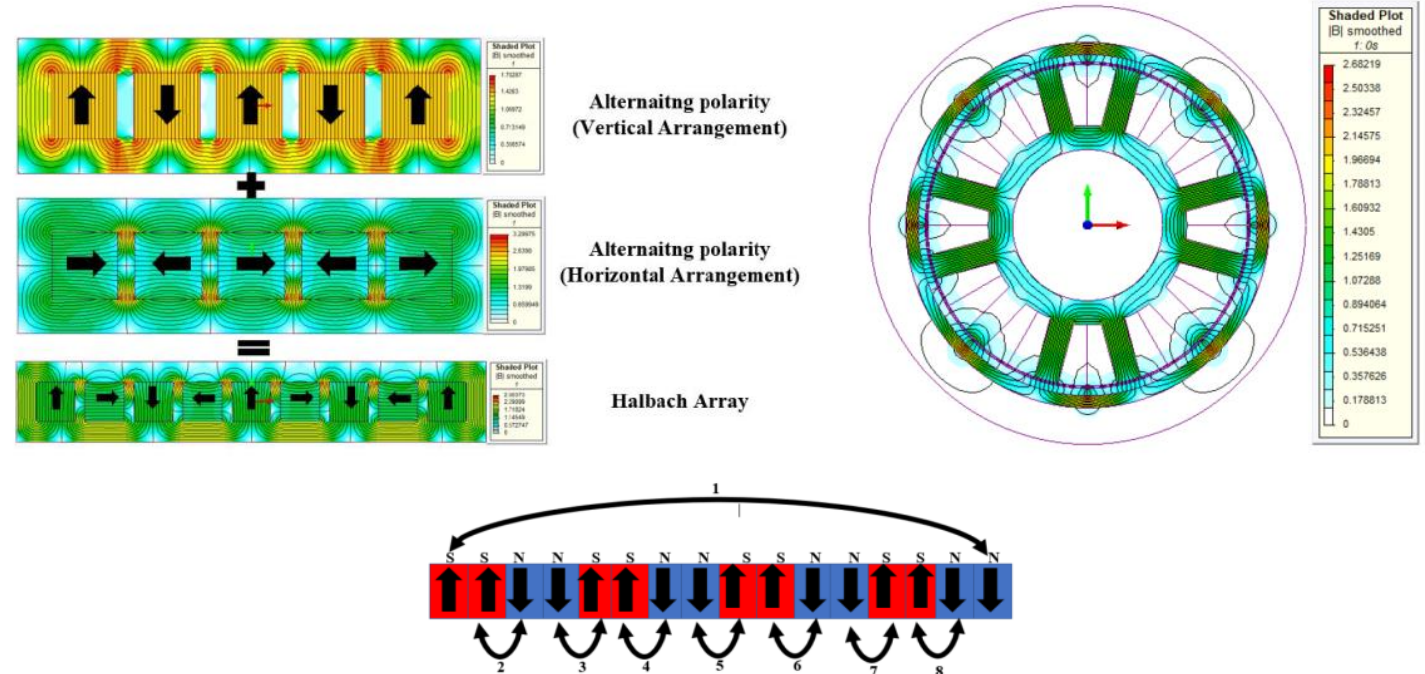

Fig 2. Halbach Array Configuration and Magnetic Flux Dispersion in PMSG

Although the waveform emitted by the generator is an alternating sinusoidal wave (AC) In fact, this is the most common magnetization pattern for this shape of magnets: first, since the air-gap flux density has a sinusoidal wave form[14] with a frequency power is converted into fixed frequency[15] that varies with the speed of the generator rotation, a controller containing filters, rectifiers, and other components is required to control the output provided by the generator. The rectifier will be modelled as an electrical circuit schematic in the simulation software shown in Figure 3, with the power input and output is expressed by equation (6) (8), angular speed is expressed by equation (7). Where $\mathrm{P}$ is the generator power (Watt), $\mathrm{T}$ is the load torque $(\mathrm{Nm}), \omega$ is the angular speed ( $\mathrm{rad} / \mathrm{s}$ ), and $\mathrm{n}$ is the rotation speed (rpm), $\mathrm{V}$ is the voltage (Volt), and I is the current (Ampere). The efficiency of the generator can be calculated using equation (9) with $\eta$ is efficiency (\%), Pin is input power (Watts), and Pout is output power (Watts). As for Table 2-4 shows the performance parameters produced in this our design.

$$
\begin{aligned}
& P_{\text {in }}=T \times \omega \\
& \omega=\frac{2 \pi \cdot n}{60} \\
& P_{\text {out }}=V \times I \\
& \eta=\frac{P_{\text {in }}}{P_{\text {out }}} \times 100 \%
\end{aligned}
$$




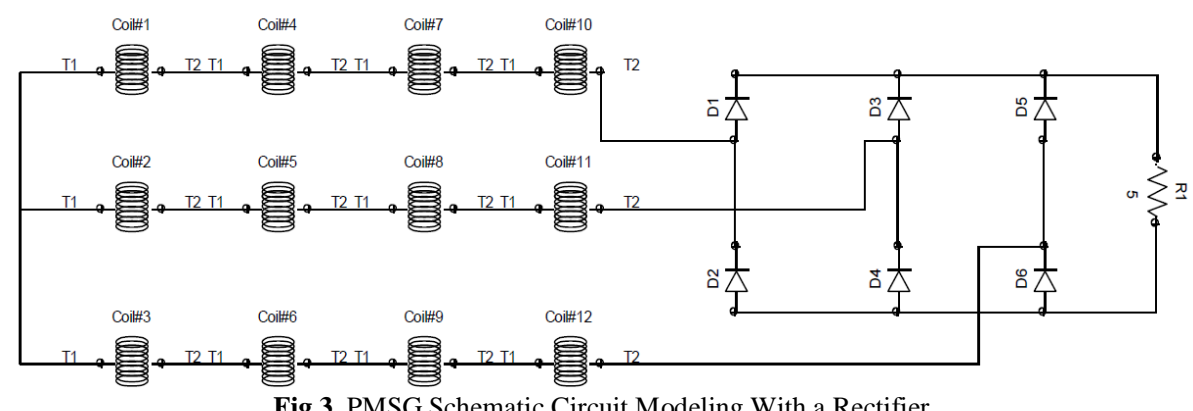

Fig 3. PMSG Schematic Circuit Modeling With a Rectifier

Table 2. The Voltage Values Generated by The Initial Design of PMSG

\begin{tabular}{cccccc}
\hline \multirow{2}{*}{ Load } & \multicolumn{5}{c}{ Various Speeds (Rpm) } \\
\cline { 2 - 6 } & 1000 & 2000 & 3000 & 4000 & 5000 \\
\cline { 2 - 6 } $\mathbf{5} \boldsymbol{\Omega}$ & 106.89 & 142.99 & 146.35 & 148.35 & 151.68 \\
\hline $\mathbf{1 5} \boldsymbol{\Omega}$ & 144.99 & 251.25 & 325.47 & 370.16 & 398.31 \\
\hline $\mathbf{3 0} \boldsymbol{\Omega}$ & 156.97 & 293.75 & 401.91 & 503.77 & 585.72 \\
\hline $\mathbf{6 0} \boldsymbol{\Omega}$ & 161.39 & 312.00 & 443.87 & 577.05 & 688.70 \\
\hline $\mathbf{1 0 0} \boldsymbol{\Omega}$ & 164.83 & 320.88 & 470.60 & 611.00 & 741.34 \\
\hline
\end{tabular}

Table 3. The Current Values Generated by The Initial Design of PMSG

\begin{tabular}{cccccc}
\hline \multirow{2}{*}{ Load } & \multicolumn{5}{c}{ Various Speeds (Rpm) } \\
\cline { 2 - 6 } & 1000 & 2000 & 3000 & 4000 & 5000 \\
\cline { 2 - 6 } $\mathbf{5} \boldsymbol{\Omega}$ & 21.38 & 28.60 & 29.27 & 29.80 & 30.34 \\
\hline $\mathbf{1 5} \boldsymbol{\Omega}$ & 9.67 & 16.75 & 21.70 & 24.68 & 26.55 \\
\hline $\mathbf{3 0} \boldsymbol{\Omega}$ & 5.23 & 9.79 & 13.40 & 16.79 & 19.52 \\
\hline $\mathbf{6 0} \boldsymbol{\Omega}$ & 2.69 & 5.20 & 7.40 & 9.62 & 11.48 \\
\hline $\mathbf{1 0 0} \boldsymbol{\Omega}$ & 1.65 & 3.21 & 4.71 & 6.11 & 7.41 \\
\hline
\end{tabular}

Table 4. The Power Input Values Generated by The Initial Design of PMSG

\begin{tabular}{cccccc}
\hline \multirow{2}{*}{ Load } & \multicolumn{5}{c}{ Various Speeds (Rpm) } \\
\cline { 2 - 6 } & 1000 & 2000 & 3000 & 4000 & 5000 \\
\cline { 2 - 6 } Power Input Values $(\mathbf{W})$ \\
\hline $\mathbf{5} \boldsymbol{\Omega}$ & 2696.29 & 4846.23 & 5281.75 & 5683.95 & 6652.23 \\
\hline $\mathbf{1 5} \boldsymbol{\Omega}$ & 1664.30 & 4924.48 & 8325.50 & 10843.86 & 12737.93 \\
\hline $\mathbf{3 0} \boldsymbol{\Omega}$ & 1019.32 & 3508.62 & 6670.47 & 10307.31 & 13973.33 \\
\hline $\mathbf{6 0} \boldsymbol{\Omega}$ & 613.78 & 2161.36 & 4428.78 & 7293.18 & 10436.16 \\
\hline $\mathbf{1 0 0} \boldsymbol{\Omega}$ & 435.95 & 1552.25 & 3282.16 & 5394.02 & 8001.78 \\
\hline
\end{tabular}

Explanation from table 2 on the initial configuration, the voltage provided by the design of PMSG 12 Slots and 8 Poles outer-runner is proportional to the speed and large load. And the higher the rpm, the greater the magnetic flux produced by the movement of the magnetic field, and a broad coil magnetic flux obtained would result in a higher induced voltage. Because the load placed on the circuit is a resistive load one that causes much current to be blocked, the current absorbed by the load is directly proportional to the speed and inversely proportional to the load, because the load is directly proportional to the speed and inversely proportional to the load. The higher the rotational speed, the more often the coil or coil will miss lines of magnetic flux, resulting in higher induced voltage and current flows in the coils that emerge shown by table 3 . In table 4 equation (6)-(8) used for the power input is proportional to the product of the torque at the load (T) and $\omega$, where is the multiple of $2 \pi$ with the speed in rpm divided by time, so the input power will increase as the speed increases. The power output will be lower at high loads because the amount of torque will be less, as seen in Table 5 and 6 .

Table 5. The Power Output Values Generated by The Initial Design of PMSG

\begin{tabular}{cccccc}
\hline \multirow{2}{*}{ Load } & \multicolumn{5}{c}{ Various Speeds (Rpm) } \\
\cline { 2 - 6 } & 1000 & 2000 & 3000 & 4000 & 5000 \\
\cline { 2 - 6 } $\mathbf{5} \boldsymbol{\Omega}$ & 2285.09 & 4096.66 & 4301.64 & 4468.60 & 4643.32 \\
\hline $\mathbf{1 5} \boldsymbol{\Omega}$ & 1417.54 & 4214.89 & 7062.81 & 9144.71 & 10595.04 \\
\hline $\mathbf{3 0} \boldsymbol{\Omega}$ & 834.90 & 2905.90 & 5414.24 & 8470.91 & 11437.18 \\
\hline $\mathbf{6 0} \boldsymbol{\Omega}$ & 444.15 & 1649.08 & 3334.81 & 5602.21 & 7964.14 \\
\hline $\mathbf{1 0 0} \boldsymbol{\Omega}$ & 277.16 & 1058.44 & 2267.84 & 3800.09 & 5593.04 \\
\hline
\end{tabular}

Table 6. The Torque Values Generated by The Initial Design of PMSG

\begin{tabular}{rccccc}
\hline \multirow{2}{*}{ Load } & \multicolumn{5}{c}{ Various Speeds (Rpm) } \\
\cline { 2 - 5 } & 1000 & 2000 & 3000 & 4000 & 5000 \\
\cline { 2 - 5 } & \multicolumn{5}{c}{ Torque Values $(\mathbf{N m})$} \\
\hline $\mathbf{5} \boldsymbol{\mathbf { 1 5 }} \boldsymbol{\Omega}$ & 27.5 & 23.14 & 16.81 & 13.27 & 11.42 \\
\hline $\mathbf{3 0} \boldsymbol{\Omega}$ & 15.89 & 23.51 & 26.50 & 25.89 & 24.33 \\
\hline $\mathbf{6 0} \boldsymbol{\Omega}$ & 5.73 & 16.75 & 21.23 & 24.61 & 26.69 \\
\hline $\mathbf{1 0 0} \boldsymbol{\Omega}$ & 4.16 & 10.32 & 14.10 & 17.41 & 19.93 \\
\hline
\end{tabular}




\section{Result and Discussion}

\subsection{Halbach Array Configuration}

Variations to the magnetic structure that previously used alternating polarity to use the halbach array configuration will be made to see if it affects the performance parameter that will be produced by retaining the diameter of each component, size, and type of material used in the initial design of the PMSG 12 slots and 8 poles outer-runner. Since the simulation models only use the fundamental sinewave current as the power source, it can be ignored that high-order voltage harmonics cause the thrust ripple to increase while the pole is on-load[16]. This magnetic arrangement is achieved by inserting one piece of magnet between the two previous magnets, as seen in Figure 4 . For the dimension, type of material in this variation design is the same as in the initial design methodology, while the modeling form for simulation and the distribution of magnetic flux resulting from the simulation are shown. as seen in Figure 5. The following figure depicts the performance parameter data produced by this variation.

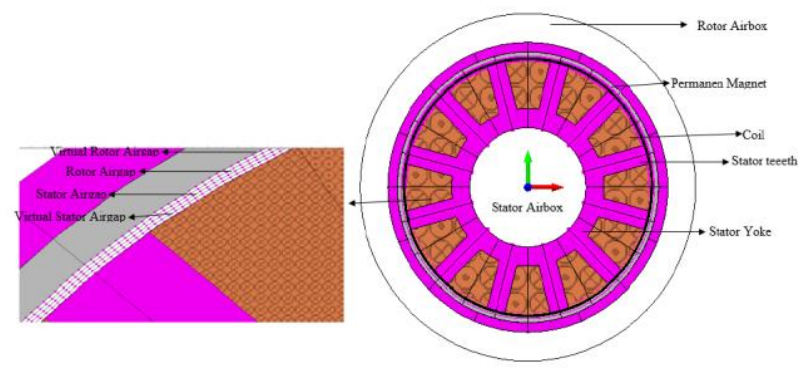

Fig 4. Design of PMSG 12S 8P Outer-Runner With Halbach Array Configuration
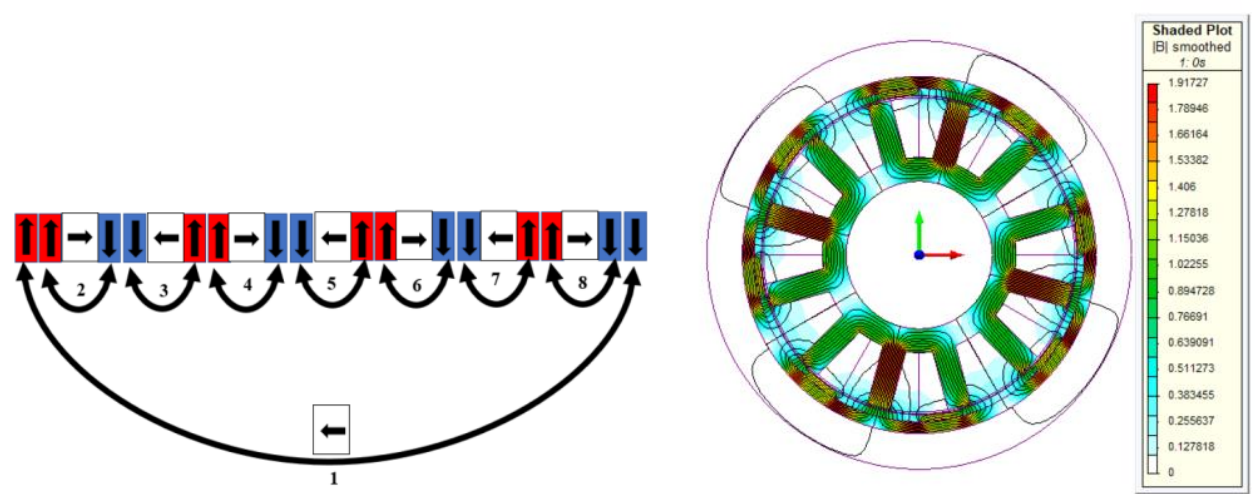

Fig 5. Magnetic Structure Variations in Halbach Array and Flux Dispersion Halbach Array in PMSG

Table 7. The Voltage Values Generated by Halbach Array Configuration in PMSG

\begin{tabular}{crrrrr}
\hline \multirow{2}{*}{ Load } & \multicolumn{5}{c}{ Various Speeds (Rpm) } \\
\cline { 2 - 6 } & 1000 & \multicolumn{5}{c}{ Voon 3000} & 4000 & 5000 \\
\cline { 2 - 6 } & \multicolumn{5}{c}{ Voltage Values (V) } \\
\hline $\mathbf{5 \Omega}$ & 114.99 & 130.02 & 133.33 & 137.38 & 138.72 \\
\hline $\mathbf{1 5} \boldsymbol{\Omega}$ & 165.79 & 284.93 & 342.81 & 352.16 & 378.11 \\
\hline $\mathbf{3 0} \mathbf{\Omega}$ & 185.73 & 335.38 & 459.87 & 554.77 & 621.24 \\
\hline $\mathbf{6 0} \boldsymbol{\Omega}$ & 199.46 & 374.41 & 530.33 & 673.04 & 810.95 \\
\hline $\mathbf{1 0 0} \boldsymbol{\Omega}$ & 207.40 & 399.70 & 571.71 & 739.27 & 885.36 \\
\hline
\end{tabular}

Table 8. The Current Values Generated by Halbach Array Configuration in PMSG

\begin{tabular}{cccccc}
\hline \multirow{2}{*}{ Load } & \multicolumn{5}{c}{ Various Speeds (Rpm) } \\
\cline { 2 - 6 } & 1000 & \multicolumn{5}{c}{ Current Values (A) } \\
\cline { 2 - 6 } $\mathbf{5} \boldsymbol{\mathbf { 5 }}$ & 23.00 & 26.00 & 26.67 & 27.48 & 27.74 \\
\hline $\mathbf{1 5} \mathbf{\Omega}$ & 11.05 & 19.00 & 22.85 & 23.48 & 25.21 \\
\hline $\mathbf{3 0} \mathbf{\Omega}$ & 6.19 & 11.18 & 15.33 & 18.49 & 20.71 \\
\hline $\mathbf{6 0} \boldsymbol{\Omega}$ & 3.32 & 6.24 & 8.84 & 11.22 & 13.52 \\
\hline $\mathbf{1 0 0} \boldsymbol{\Omega}$ & 2.07 & 4.00 & 5.72 & 7.39 & 8.85 \\
\hline
\end{tabular}

Table 9. The Power Input Values Generated by Halbach Array Configuration in PMSG

\begin{tabular}{cccccc}
\hline \multirow{2}{*}{ Load } & \multicolumn{5}{c}{ Various Speeds (Rpm) } \\
\cline { 2 - 6 } & 1000 & \multicolumn{5}{c}{3000} & 4000 & 5000 \\
\cline { 2 - 6 } $\mathbf{5} \boldsymbol{\Omega}$ & 3021.51 & 3900.39 & 4229.55 & 4599.33 & 5272.94 \\
\hline $\mathbf{1 5} \boldsymbol{\Omega}$ & 2073.36 & 6093.28 & 8884.42 & 9531.07 & 10938.70 \\
\hline $\mathbf{3 0} \boldsymbol{\Omega}$ & 1369.70 & 4351.44 & 8246.47 & 11985.05 & 15088.96 \\
\hline $\mathbf{6 0} \boldsymbol{\Omega}$ & 862.43 & 2925.79 & 5788.84 & 9297.43 & 13513.07 \\
\hline $\mathbf{1 0 0} \boldsymbol{\Omega}$ & 599.64 & 2127.98 & 4332.79 & 7094.30 & 10338.88 \\
\hline
\end{tabular}


Table 10. The Power Output Values Generated by Halbach Array Configuration in PMSG

\begin{tabular}{cccccc}
\hline \multirow{2}{*}{ Load } & \multicolumn{5}{c}{ Various Speeds (Rpm) } \\
\cline { 2 - 6 } & 1000 & 2000 & 3000 & 4000 & 5000 \\
\cline { 2 - 6 } $\mathbf{5} \boldsymbol{\Omega}$ & 2653.29 & 3387.90 & 3564.59 & 3788.60 & 3879.50 \\
\hline $\mathbf{1 5} \boldsymbol{\Omega}$ & 1834.27 & 5428.89 & 7860.56 & 8296.67 & 9550.71 \\
\hline $\mathbf{3 0} \boldsymbol{\Omega}$ & 1157.84 & 3753.94 & 7074.79 & 10296.97 & 12914.67 \\
\hline $\mathbf{6 0} \boldsymbol{\Omega}$ & 683.10 & 2352.13 & 4689.46 & 7559.78 & 10980.54 \\
\hline $\mathbf{1 0 0} \boldsymbol{\Omega}$ & 448.09 & 1627.59 & 3287.89 & 5472.53 & 7842.88 \\
\hline
\end{tabular}

Table 11. The Torque Values Generated by Halbach Array Configuration in PMSG

\begin{tabular}{cccccc}
\hline \multirow{2}{*}{ Load } & \multicolumn{5}{c}{ Various Speeds $(\mathbf{R p m})$} \\
\cline { 2 - 6 } & 1000 & 2000 & 3000 & 4000 & 5000 \\
\cline { 2 - 6 } $\mathbf{5} \boldsymbol{\Omega}$ & 28.85 & 18.62 & 13.46 & 10.64 & 8.76 \\
\hline $\mathbf{1 5} \boldsymbol{\Omega}$ & 19.80 & 29.09 & 28.28 & 22.75 & 20.89 \\
\hline $\mathbf{3 0} \boldsymbol{\Omega}$ & 13.08 & 20.78 & 26.25 & 28.61 & 28.82 \\
\hline $\mathbf{6 0} \boldsymbol{\Omega}$ & 8.24 & 13.97 & 18.43 & 22.20 & 25.81 \\
\hline $\mathbf{1 0 0} \boldsymbol{\Omega}$ & 5.73 & 10.16 & 13.79 & 16.94 & 19.75 \\
\hline
\end{tabular}

The PMSG 12 slots and 8 poles outer-runner increased voltage through different loads and speeds is increased by applying the halbach array application to the initial design used. This is when the addition of a magnetic slice between the two polarities allows the inner side of the magnet to have a greater magnetic field than the outer side, resulting in a higher linkage flux obtained by the coil, as seen in Figure 5 above, where all areas of the teeth and coil are exposed to magnetic flux lines.

\subsection{Initial Designs PMSG Compared to Halbach Array Configuration}

The following graph represents a summary between the initial design and the simulation results of the halbach array configuration. Where the voltage in the halbach array configuration has decreased when using loads of 5 and $15 \mathrm{ohms}$, as seen in Table 7 above, as well as the conditions that exist in the resulting current when using loads greater than 30 ohms, as shown in Table 8 above. The PMSG 12 Slots and 8 Poles result in increased voltage and output current due to increased output power, For more details, we present a comparison graph below.

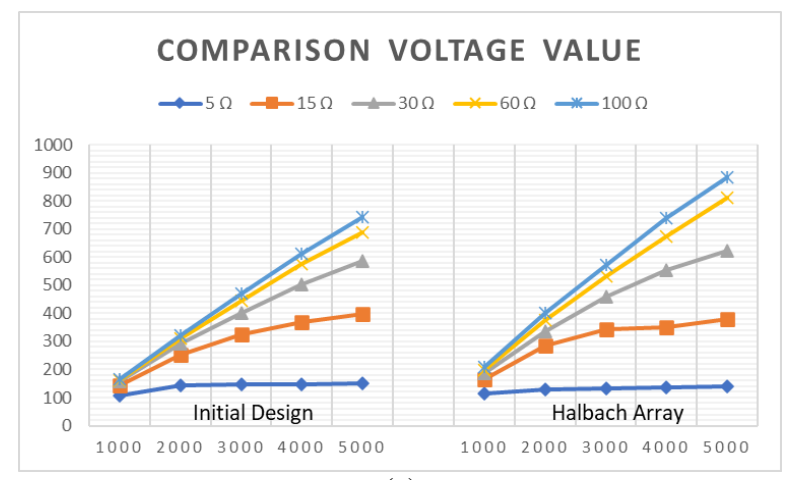

(a)

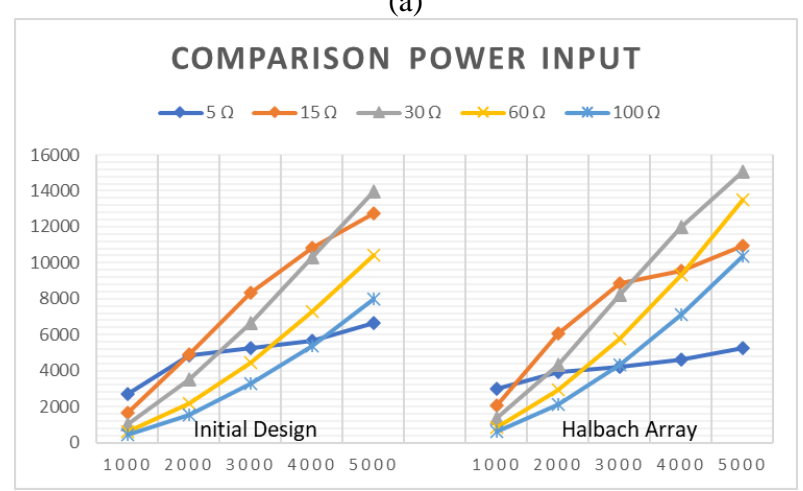

(c)

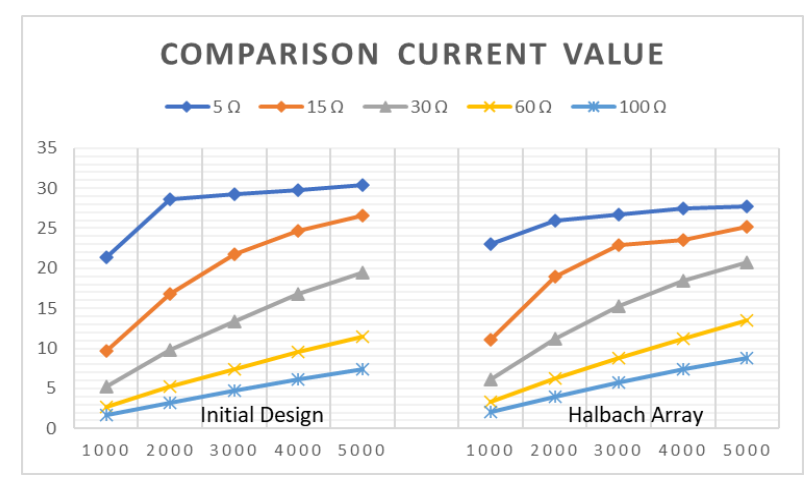

(b)

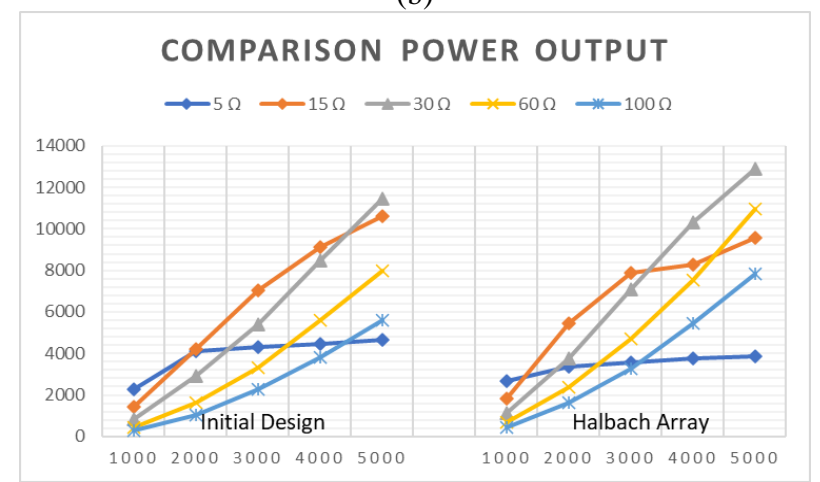

(d) 


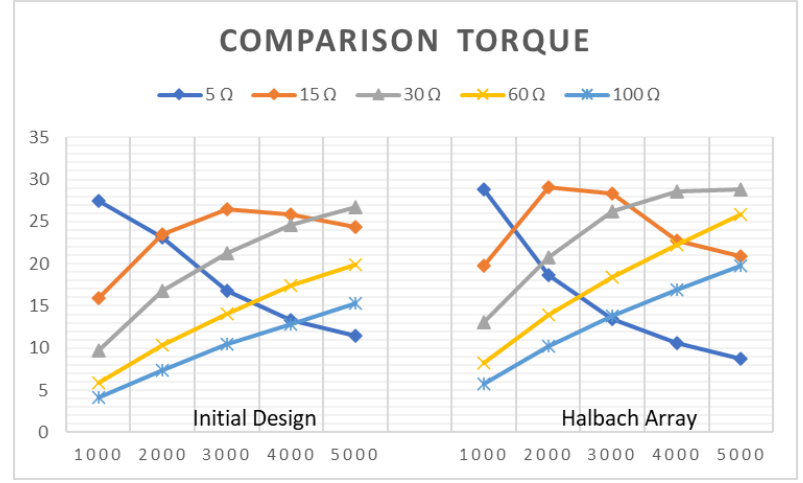

(e)

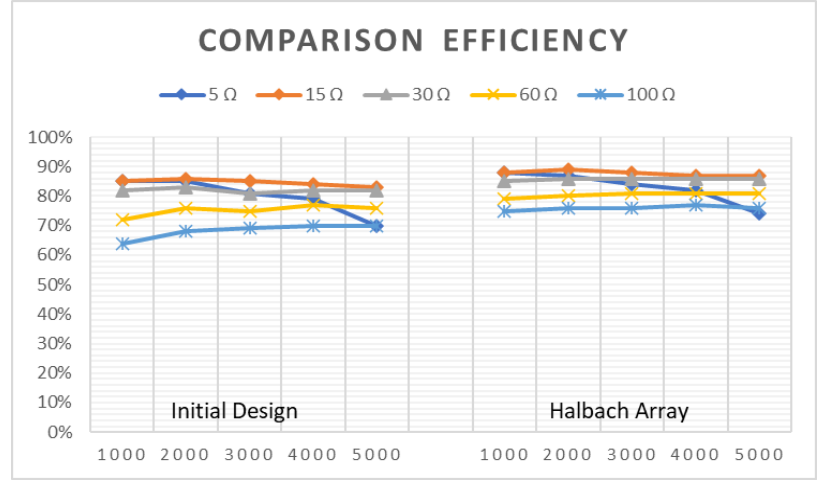

(f)

Fig 6. Comparison Result Between Initial Design and Halbach Array Configuration in PMSG

The output power provided by the PMSG 12 slots and 8 poles outer runner using the halbach array magnetic configuration is similar to the required input power, increasing the efficiency of this PMSG. Over all speeds and loads used, as seen in the comparison data above. Because of the change in magnetic configuration, there are more magnetic fields dispersed within, resulting in longer magnetic flux lines. However, as previously said, at low load, PMSG encounters a reasonably high transient condition before reaching a point of stability, resulting in a significant reduction in performance. Based on the result of this research, it can be concluded that causes radial force variations through rub between the rotor and stator, as opposed to the smooth constant rub used in simulations. The control technique will remove jump reaction modes and minimize mechanical stress considerably with minor transients at the switching instants, the induction generator's terminal voltage, stator current, $\mathrm{rpm}$, active power generation, and reactive power consumption remain constant at their previous values. In order to find such materials, the electric machine must have a moderate air gap [13][17][18][19]. So, reactive power supplied by a windturbine system in synchronous condenser mode is the same as that supplied by a synchronous engine. Since the current magnitude is different in this mode of operations[20][21], we presume that our design PMSG can meet the reactive power compliance criterion when connected to the grid.

\section{Conclusion}

The magnetic field within the generator can be increased by using the halbach array magnetic configuration depending on the resulting flux distribution, but the voltage produced at a $5 \mathrm{ohm}$ load only increases at $1000 \mathrm{rpm}$, which results in 8.1 volts more and decreases at the same distance. Others, although the voltage rises at speeds of 1000, 2000, and $3000 \mathrm{rpm}$ with a load of 15 ohms, it declines at speeds of 4000 and $5000 \mathrm{rpm}$. At 30, 60, and $100 \mathrm{ohm}$ loads, the pace increases. Meanwhile, since the resulting current and torque are the same independent of voltage, the configuration of this variation is ideal for use with loads less than $30 \mathrm{ohm}$. The increase in torque causes an increase in the amount of input power, which is proportional to the speed and also the amount of torque, where the input power increases at all speeds at the load of $30 \mathrm{ohm}$. This also happens to the output power produced at the load of $30 \mathrm{ohm}$, with a percentage increase greater than the increase in input power, resulting in a large efficiency with the load of $30 \mathrm{ohm}$ it over $86 \%$. Further research suggestions are in the process of developing the PMSG required tangible form using a low-cost, as well as the availability of component content. In order to realize the actual shape of the generator, PMSG must consider other elements of the state, such as the halbach array, which, if imposed, would overheat before rush the generator itself and variations design on the stator teeth that umbrella added..

\section{References}

[1] M. Kimura et al., "A study of permanent magnet rotor for large scale wind turbine generator system," Proc. - 2012 20th Int. Conf. Electr. Mach. ICEM 2012, pp. 1161-1171, 2012, doi: 10.1109/ICElMach.2012.6350023.

[2] I. Sai and B. Kumar, "Direct control technique for PMSG based Variable speed Wind Applications," in International Conference on Electrical, Electronics, and Optimization Techniques (ICEEOT) - 2016, 2016, pp. 2543-2548.

[3] O. Solomon, "The design, control and dynamic performance of an interior permanent magnet synchronous generator for wind power system," Proc. IECON 2018 - 44th Annu. Conf. IEEE Ind. Electron. Soc., vol. 1, pp. 714-718, 2018, doi: 10.1109/IECON.2018.8591728.

[4] S. Baqaruzi and S. T. Kasim, "Comparison of Effect Efficiency and Voltage Regulation Between Three-Phase Transformer Winding Connections," Bull. Comput. Sci. Electr. Eng., vol. 1, no. 2, pp. 54-62, 2020, doi: 10.25008/bcsee.v1i2.1123.

[5] T. Fukami, Y. Matsuura, K. Shima, M. Momiyama, and M. Kawamura, "A multipole synchronous machine with nonoverlapping concentrated armature and field windings on the stator," IEEE Trans. Ind. Electron., vol. 59, no. 6, pp. 2583-2591, 2012, doi: 10.1109/TIE.2011.2157293.

[6] Y. Rakhmanova, L. Roginskaya, A. Lobanov, and Z. Yalalova, "Production of Plate Magnet Cores in Modern Transformers," Proc. - ICOECS 2019 2019 Int. Conf. Electrotech. Complexes Syst., 2019, doi: 10.1109/ICOECS46375.2019.8949913.

[7] C. He and T. Wu, "Analysis and design of surface permanent magnet synchronous motor and generator," CES Trans. Electr. Mach. Syst., vol. 3, no. 1, pp. 94-100, 2019, doi: 10.30941/cestems.2019.00013.

[8] M. H. Zamani, G. H. Riahy, and M. Abedi, "Rotor-speed stability improvement of dual stator-winding induction generator-based wind farms by controlwindings voltage oriented control," IEEE Trans. Power Electron., vol. 31, no. 8, pp. 5538-5546, 2016, doi: 10.1109/TPEL.2015.2495256.

[9] F. Jin, J. Si, Z. Cheng, P. Su, L. Dong, and G. Qi, "Optimization Design of A Novel Toroidal-Winding Permanent Magnet Synchronous Generator," 2019 22nd Int. Conf. Electr. Mach. Syst. ICEMS 2019, 2019, doi: 10.1109/ICEMS.2019.8921858.

[10] S. K. Gupta, A. Dwivedi, and R. K. Srivastava, "Fabrication of dual-stator Permanent magnet synchronous generator," 12th IEEE Int. Conf. Electron. Energy, Environ. Commun. Comput. Control (E3-C3), INDICON 2015, pp. 2-7, 2016, doi: 10.1109/INDICON.2015.7443782.

[11] X. L. Wang, X. L. Ma, and X. Z. Yuan, "Analysis of magnetic field for inner rotor coreless permanent magnet machines with Halbach array," 2011 Int. Conf. Appl. Supercond. Electromagn. Devices, ASEMD 2011, vol. 0, no. 1, pp. 335-338, 2011, doi: 10.1109/ASEMD.2011.6145138.

[12] L. Duan, H. Lu, C. Zhao, and H. Shen, "Influence of Different Halbach Arrays on Performance of Permanent Magnet Synchronous Motors," Proc. 2020 IEEE Int. Conf. Artif. Intell. Comput. Appl. ICAICA 2020, pp. 994-998, 2020, doi: 10.1109/ICAICA50127.2020.9182625.

[13] T. Sakamoto, "Magnetic stress and support plate deflection of halbach array magnets," Proc. - 2012 20th Int. Conf. Electr. Mach. ICEM 2012, pp. 1352-1357, 2012, doi: 10.1109/ICElMach.2012.6350053.

[14]B. Virlan, A. Munteanu, L. Livadaru, A. Simion, and I. Nacu, "Pole magnets segmentation effect on permanent magnet synchronous generators," 2017 
11th Int. Conf. Electromechanical Power Syst. SIELMEN 2017 - Proc., vol. 2017-Janua, pp. 163-168, 2017, doi: 10.1109/SIELMEN.2017.8123318.

[15] S. V. Devi and Dr. N.Senthil Kumar, "Design of Power Electronic Transformer Based Variable Speed Wind Energy Conversion System," in International Conference on Circuit, Power and Computing Technologies [ICCPCT], 2016, pp. 199-203.

[16] X. Huang, Z. Qian, Q. Tan, J. Li, and B. Zhou, "Suppressing the thrust ripple of the permanent magnet linear synchronous motors with different pole structures by setting the modular primary structures differently," IEEE Trans. Energy Convers., vol. 33, no. 4, pp. 1815-1824, 2018, doi: 10.1109/TEC.2018.2842077.

[17] S. P. Gawande, K. B. Porate, K. L. Thakre, and G. L. Bodhe, "Synchronization of synchronous generator and induction generator for voltage \& frequency stability using STATCOM," Proc. - 3rd Int. Conf. Emerg. Trends Eng. Technol. ICETET 2010, pp. 407-412, 2010, doi: 10.1109/ICETET.2010.154

[18] C. Chamroon, M. O. T. Cole, and T. Wongratanaphisan, "An active vibration control strategy to prevent nonlinearly coupled rotor-stator whirl responses in multimode rotor-dynamic systems," IEEE Trans. Control Syst. Technol., vol. 22, no. 3, pp. 1122-1129, 2014, doi: 10.1109/TCST.2013.2265740.

[19] J. T. Shi, X. Liu, D. Wu, and Z. Q. Zhu, "Influence of stator and rotor pole arcs on electromagnetic torque of variable flux reluctance machines," IEEE Trans. Magn., vol. 50, no. 11, 2014, doi: 10.1109/TMAG.2014.2330363.

[20] L. L. Amuhaya and M. J. Kamper, "Effect of rotor field winding MMF on performance of grid-compliant hybrid-PM slip synchronous wind generator," IEEE PES PowerAfrica Conf. PowerAfrica 2016, pp. 254-258, 2016, doi: 10.1109/PowerAfrica.2016.7556612.

[21] P. Roshanfekr, S. Lundmark, T. Thiringer, and M. Alatalo, "A synchronous reluctance generator for a wind application-compared with an interior mounted permanent magnet synchronous generator," IET Conf. Publ., vol. 2014, no. 628 CP, pp. 3-7, 2014, doi: 10.1049/cp.2014.0411. 